\title{
The Impact of Ventilator-Associated Events in Critically Ill Subjects With Prolonged Mechanical Ventilation
}

\author{
Hidetsugu Kobayashi MD, Shigehiko Uchino MD, Masanori Takinami MD, \\ and Shoichi Uezono MD
}

\begin{abstract}
BACKGROUND: The Centers for Disease Control and Prevention recently released a surveillance definition for respiratory complications in ventilated patients, ventilator-associated events (VAEs), to replace ventilator-associated pneumonia (VAP). VAEs consist of ventilator-associated conditions (VAC), infection-related ventilator-associated complications (IVAC), and possible VAP. A duration of mechanical ventilation of at least $4 \mathrm{~d}$ is required to diagnose VAE. However, the observed duration of mechanical ventilation was $<4 \mathrm{~d}$ in many previous studies. We evaluated the impact of VAEs on clinical outcomes in critically ill subjects who required mechanical ventilation for $\geq 4 \mathrm{~d}$. METHODS: This single-center retrospective cohort study was conducted in the general ICU of an academic hospital. We included 407 adult subjects who were admitted to the ICU and required mechanical ventilation for at least $4 \mathrm{~d}$. VAC and IVAC were identified from the electronic medical records. VAP was defined according to the Centers for Disease Control and Prevention 2008 criteria and was identified from the surveillance data of the infection control team of our hospital. Clinical outcomes were studied in the VAC, IVAC, and VAP groups. Possible VAP was not investigated. RESULTS: Higher mortality was seen in VAC and IVAC subjects, but not in VAP subjects, compared with those without VAEs and VAP. By multivariable hazard analysis for hospital mortality, IVAC was independently associated with hospital mortality (hazard ratio $2.42,95 \%$ CI 1.39-4.20, $P=.002$ ). VAC also tended to show a similar association with hospital mortality (hazard ratio $1.45,95 \%$ CI $0.97-2.18, P=.07)$. On the other hand, VAP did not increase a hazard of hospital death (hazard ratio 1.08, 95\% CI $0.44-2.66, P=.87$ ). CONCLUSIONS: We found that a VAE was related to hospital mortality in critically ill subjects with prolonged mechanical ventilation, and that VAP was not. Key words: mechanical ventilation; complication; ventilator-associated pneumonia; ventilator-associated event; prolonged mechanical ventilation. [Respir Care 2017;62(11):1379-1386. @ 2017 Daedalus Enterprises]
\end{abstract}

\section{Introduction}

Ventilator-associated pneumonia (VAP) is a major morbidity in patients with mechanical ventilation, and many hospitals regard VAP as an important nosocomial infection. ${ }^{1-3}$ However, it is difficult to diagnose VAP accurately because the diagnostic criteria include subjective and non-

Drs Kobayashi, Uchino, and Takinami are affiliated with the Intensive Care Unit, Department of Anesthesiology, Jikei University School of Medicine, Tokyo, Japan. Dr Uezono is affiliated with the Department of Anesthesiology, Jikei University School of Medicine, Tokyo, Japan.

Dr Uezono discloses a relationship with Edwards Lifesciences Corporation Japan. The other authors have disclosed no conflicts of interest. specific measures such as chest radiography and sputum conditions. ${ }^{1}$ Therefore, alternative quality benchmarking for mechanically ventilated patients has been sought in the past decade. ${ }^{4-8}$ In 2013, the United States Centers for Disease Control and Prevention (CDC) established a surveillance definition, ventilator-associated events (VAEs). ${ }^{8,9}$ VAE consists of ventilator-associated conditions (VAC),

Correspondence: Hidetsugu Kobayashi MD, Intensive Care Unit, Department of Anesthesiology, Jikei University School of Medicine, 3-19-18, Nishi-Shinbashi, Minato-ku, Tokyo, Japan, 105-8471. E-mail: hidetsugu-evfr@jikei.ac.jp.

DOI: $10.4187 /$ respcare. 05073 


\section{VAEs in CRitically Ill SubJects With PMV}

infection-related ventilator-associated complications (IVAC, a subset of VAC with infectious signs), and possible VAP (IVAC with microbiological evidence of pneumonia). Several studies have shown that VAC and IVAC

\section{See the Related Editorial on Page 1501}

were associated with morbidity and mortality, and that the relationship between VAC (or IVAC) in new VAE criteria and VAP in the previous 2008 CDC's definition was poor. ${ }^{10-14}$

To diagnose a VAE, sustained deterioration of oxygenation for at least $2 \mathrm{~d}$ after stability or improvement on the ventilator for $\geq 2$ consecutive days is needed. However, in most previous studies validating the VAE definition, the duration of mechanical ventilation was defined as $\geq 48 \mathrm{~h},{ }^{10,11,14,15}$ or at least 2 d. ${ }^{12,13,16}$ The duration of mechanical ventilation in those studies did not meet the minimal requirement of the VAE definition (at least $4 \mathrm{~d}$ in total). We speculated that the shorter duration of mechanical ventilation in those studies than that of VAE criteria might affect the results. Therefore, in this study, we included only subjects who required prolonged mechanical ventilation $\geq 4 \mathrm{~d}$ to strictly follow the VAE definition, and we investigated the impact of VAC, IVAC, and VAP in the CDC's 2008 criteria on patient outcome. We also examined the relationship between VAC, IVAC, and VAP.

\section{Methods}

This was a single-center retrospective cohort study, conducted in a 20-bed general ICU of an academic hospital in Tokyo, Japan. The Investigational Review Board of Jikei University hospital reviewed the study protocol, and the need for informed consent was waived because of the anonymous and retrospective design.

\section{Study Population}

All patients who were admitted to the ICU between January 1, 2010, and December 31, 2013, were screened retrospectively. We included subjects who were $\geq 18 \mathrm{y}$ old and required mechanical ventilation for $\geq 4 \mathrm{~d}$. Patients treated with extracorporeal membrane oxygenation or highfrequency oscillatory ventilation were excluded. We identified VAC and IVAC in the study population according to the new VAE definition, however possible VAP was not examined in this study. ${ }^{9}$ Our laboratory reports only semiquantitative results without a count of neutrophils and squamous epithelial cells for sputum culture, which made it difficult to diagnose possible VAP. VAP subjects during the study period were identified in the VAP surveillance database maintained by the infection control team of our hospital, based on previous 2008 CDC criteria, usually

\section{QUICK LOOK}

\section{Current knowledge}

The Centers for Disease Control and Prevention recently introduced a ventilator-associated event (VAE) surveillance definition in mechanically ventilated patients in place of ventilator-associated pneumonia 2008 criteria. VAEs consist of a ventilator-associated condition, an infection-related ventilator-associated complication, and possible ventilator-associated pneumonia. VAE have been reported in recent studies to be associated with adverse outcomes.

\section{What this paper contributes to our knowledge}

We included only subjects who required prolonged mechanical ventilation ( $\geq 4 \mathrm{~d}$ ) to strictly follow the VAE definition and used a time-varying method to study the impact of a VAE and ventilator-associated pneumonia on clinical outcomes. We found that infection-related ventilator-associated complications were independently associated with hospital mortality and that ventilatorassociated pneumonia by the Centers for Disease Control and Prevention 2008 criteria did not increase the hazard for hospital death. A VAE, especially an infection-related ventilator-associated complication, is a reasonable marker for surveillance in prolonged mechanically ventilated patients.

pneumonia criteria 1, which consists of radiographic findings, clinical signs or symptoms, and laboratory data (leukopenia or leukocytosis). Microbiological tests are not needed to diagnose clinical pneumonia. ${ }^{1}$ Therefore, cut-off values in semiquantitative sputum culture to diagnose VAP were not established in our VAP surveillance. In our usual practice, we requested a chest radiograph once a day in ventilated patients to confirm the tracheal tube and catheters. Furthermore, regardless of the surveillance protocol (2008 VAP definition or 2013 VAE criteria), microbiological tests (tracheal aspirate was usually used) were examined when we suspected respiratory infection in ventilated subjects by worsening gas exchange, change in sputum characteristics, chest radiographic findings, white blood cell count, body temperature, and so on.

\section{Data Collection}

From the computerized ICU database, we retrieved the following subject characteristics: age, gender, height, weight, Acute Physiology and Chronic Health Evaluation II (APACHE II) score, ${ }^{17}$ duration from hospital admission to ICU admission, ICU admission type, ICU readmission 


\section{VAEs in CRitically Ill SubJects With PMV}

within consecutive hospitalization, comorbidities, requirement of tracheostomy and renal replacement therapy in the ICU, and clinical outcomes. To identify VAC and IVAC, we also collected the following data from the electronic medical records: daily minimum $\mathrm{F}_{\mathrm{IO}_{2}}$ and PEEP, body temperature, white blood cell count, and antimicrobial agent use. ${ }^{9}$ The primary outcome was hospital mortality. We took time-varying confounding of ventilated patients and competing events (eg, liberation from mechanical ventilation, discharge alive or dead within $3 \mathrm{~d}$ from ICU admission) into account to evaluate the impact of VACs to hospital mortality. Secondary outcomes included ICU mortality, duration of mechanical ventilation, ICU length of stay, and hospital length of stay.

\section{Statistical Analysis}

The characteristics and outcomes of VAE (VAC and IVAC) and VAP subjects were studied by descriptive statistics and were presented as medians and interquartile ranges (25th to 75 th percentiles) in continuous variables or percentages in categorical data. Subjects with VAEs or VAP were not mutually exclusive. For example, subjects in the IVAC group were all included in VAC, pairwise comparisons of subjects with VAC, IVAC, and VAP to the "Without VAEs and VAP" (the rest of VAEs and VAP) group were explored, respectively. The Fisher exact test and $t$ test were used for comparisons of categorical data and continuous data, respectively. Because survival and death at hospital discharge are competing events, a causespecific hazard for hospital death was explored by the Cox proportional hazards model with multivariate baseline variables as fixed covariates and VAC as a time-dependent covariate. First, candidate confounding baseline variables (age, sex, height, weight, APACHE II score, ICU admission type, comorbidities) to cause-specific hazard for hospital death were selected by backward variables selection using the Cox proportional hazards model where both removing and staying criteria were set at $P<.05$.

Next, the cause-specific hazard for hospital death was modeled with statistically significant variables (fixed covariates) and VAC as a time-dependent covariate, and hazard ratios with $95 \%$ CI were estimated. An unadjusted hazard ratio of VAC (time-dependent covariate) was also estimated. Similar analyses were done for IVAC and VAP. The association between VAE/VAP and ICU events (eg, ICU readmission within consecutive hospitalization, renal replacement therapy, tracheostomy) was explored by odds ratios. Furthermore, the association between characteristics of VAE/VAP subjects and hospital mortality was also investigated by odds ratios. In the two-by-two contingency table including zero-cell, we used modified odds ratios by the addition of 0.5 to each cell of the study table. ${ }^{18}$ For all statistical analyses, SAS (Version 9.4) was used.

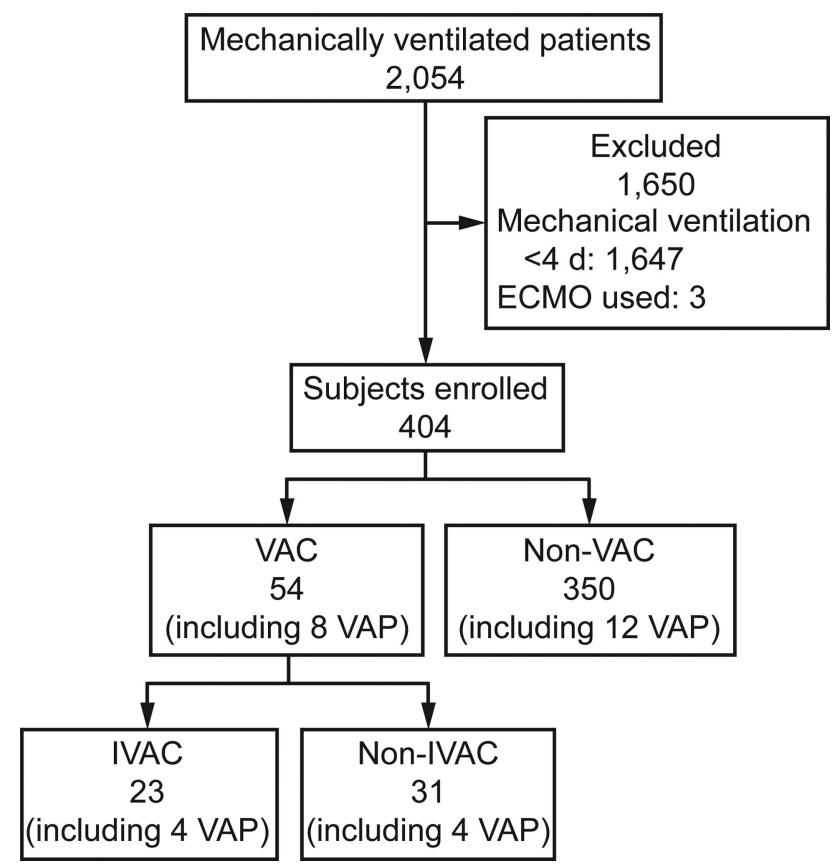

Fig. 1. Flow chart. ECMO = extracorporeal membrane oxygenation. VAC $=$ ventilator-associated condition. IVAC $=$ infectionrelated ventilator-associated complication. VAP $=$ ventilator-associated pneumonia according to the 2008 Centers for Disease Control and Prevention criteria.

\section{Results}

During the study period, 2,054 patients were intubated and received mechanical ventilation in the ICU. Of these, 407 were ventilated for $\geq 4 \mathrm{~d}$, and 3 patients were excluded because of extracorporeal membrane oxygenation use. No subjects were treated with high-frequency oscillatory ventilation during the study period. All subjects were followed up to hospital discharge, and there was no censoring in this study. The flow chart of study subjects is shown in Figure 1. A total of 54 and 23 subjects were identified as having VAC and IVAC, respectively (IVACs were a subset of the VACs). The infection control team diagnosed 21 subjects with VAP during the study period, among whom 1 subject was excluded because the duration of mechanical ventilation was $<4 \mathrm{~d}$. There were $20 \mathrm{VAP}$ subjects $(5.0 \%)$ in the study population $(N=404): 8$ subjects $(2.0 \%)$ met both VAC according to the VAE criteria and VAP according to the previous CDC's definition, and the 23 IVACs included only 4 instances of VAP. There was no strong correlation between VAE and VAP.

The median and mean days from the initiation of mechanical ventilation to the onset of VAC (or IVAC) were $4.5 \mathrm{~d}$ (25th to 75 th percentiles 3-9) and $9.2 \mathrm{~d}$ (SD $17.3 \mathrm{~d}$ ). Table 1 summarizes the characteristics of subjects with VAEs (VAC including IVAC, IVAC), VAP, and without VAEs and VAP. The median age was $68 \mathrm{y}$, and $70 \%$ of 
Table 1. Characteristics of VAEs and VAP Subjects

\begin{tabular}{|c|c|c|c|c|c|}
\hline & All Subjects & VAC & IVAC & VAP & Without VAE and VAP \\
\hline Subjects, $n(\%)$ & $404(100)$ & $54(13.4)$ & $23(5.7)$ & $20(5.0)$ & $338(83.7)$ \\
\hline Age, y (range) & $68(58-75)$ & $70(61-78)$ & $70(64-76)$ & $67(61-72)$ & $68(58-75)$ \\
\hline Male, $n(\%)$ & $283(70.0)$ & $38(70.4)$ & $17(73.9)$ & $14(70.0)$ & $237(70.1)$ \\
\hline Height, cm (IQR) & $164(156-169)$ & $164(156-171)$ & $163(156-174)$ & $164(158-174)$ & $164(156-169)$ \\
\hline Weight, kg (IQR) & $57(49-67)$ & $60(50-70)$ & $60(52-65)$ & $54(51-69)$ & $56(48-65)$ \\
\hline APACHE II score (IQR) & $23(18-29)$ & $24(19-32)$ & $24(19-30)$ & $17(14-27)^{*}$ & $23(18-29)$ \\
\hline \multicolumn{6}{|l|}{ Admission type, $n(\%)$} \\
\hline Emergency surgery & $91(22.5)$ & $8(14.8)$ & $4(17.4)$ & $3(15.0)$ & $81(24.0)$ \\
\hline Elective surgery & $120(29.7)$ & $23(42.6)^{*}$ & $9(39.1)$ & $13(65.0)^{*}$ & $90(26.6)$ \\
\hline Non-operative & $193(47.8)$ & $23(42.6)$ & $10(43.5)$ & $4(20.0)^{*}$ & $167(49.4)$ \\
\hline \multicolumn{6}{|l|}{ Comorbidities, $n(\%)$} \\
\hline Immunocompromised & $46(11.4)$ & $9(16.7)$ & $4(17.4)$ & $1(5.0)$ & $36(10.7)$ \\
\hline Metastatic cancer & $11(2.7)$ & $1(1.9)$ & $0(0)$ & $0(0)$ & $10(3.0)$ \\
\hline Hematologic malignancy & $22(5.4)$ & $4(7.4)$ & $2(8.7)$ & $0(0)$ & $19(5.6)$ \\
\hline End-stage kidney disease & $44(10.9)$ & $7(13.0)$ & $4(17.4)$ & $3(15.0)$ & $37(10.9)$ \\
\hline Liver failure & $9(2.2)$ & $2(3.7)$ & $2(8.7)$ & $0(0)$ & $7(2.1)$ \\
\hline $\begin{array}{l}\text { *P } P<.05 \text { compared to "Without VAE } \\
\text { Fisher exact test and } t \text { test were perfor } \\
\text { VAC }=\text { ventilator-associated conditio } \\
\text { IVAC }=\text { infection-related ventilator-a } \\
\text { VAP }=\text { ventilator-associated pneumon } \\
\text { VAE }=\text { ventilator-associated event } \\
\text { IQR }=\text { interquartile range }\left(25^{\text {th }} \text { to } 75^{\text {th }}\right. \\
\text { APACHE II score }=\text { acute physiology }\end{array}$ & $\begin{array}{l}\text { AP" group. } \\
\text { the comparison of cat } \\
\text { ing IVAC } \\
\text { complication } \\
\text { nters for Disease Cor } \\
\text { tiles) } \\
\text { ronic health evaluatio }\end{array}$ & $\begin{array}{l}\text { data and continuous } d \\
\text { Prevention } 2008 \text { crite }\end{array}$ & ectively. & & \\
\hline
\end{tabular}

subjects were male. Approximately half of subjects were admitted to the ICU after elective or emergent surgery. The APACHE II score was significantly lower in VAP subjects than without VAEs and VAP $(P=.02)$. The clinical courses and outcomes for subjects with VAEs, VAP, and without VAEs and VAP are summarized in Table 2. Median days on ventilation and length of ICU stay were approximately $7 \mathrm{~d}$ and $11 \mathrm{~d}$, respectively. Overall ICU and hospital mortality were $18 \%$ and $37 \%$, respectively. Indication of renal replacement therapy within ICU stay was more frequent and mortality was higher in VAC and IVAC subjects compared with subjects without VAEs and VAP. Table 3 shows the association between VAE/VAP and incidences of ICU readmission, tracheostomy/renal replacement therapy requirement in the ICU. A renal replacement therapy requirement in the ICU was significantly associated with VAC and IVAC, but not VAP.

Results of multivariable Cox proportional hazards model analysis for hospital mortality are shown in Table 4. After adjustment for confounding variables (body weight, sex male, APACHE II score, liver failure, and metastatic cancer), IVAC was independently associated with hospital mortality (hazard ratio $2.42,95 \%$ CI $1.39-4.20, P=.002$ ). VAC also tended to show a similar association with hospital mortality (hazard ratio $1.45,95 \%$ CI $0.97-2.18$, $P=.07)$. VAP was not associated with hospital death (hazard ratio $1.08,95 \% \mathrm{CI} 0.44-2.66, P=.87$ ). The association between characteristics of VAE/VAP subjects and hospital mortality is summarized in Table 5. In nonoperative subjects, VAC and IVAC were significantly associated with hospital mortality, whereas VAP was not. In subjects with comorbidities, although there was no statistical significance, odds ratios for hospital mortality tended to be higher in VAC and IVAC compared with VAP.

\section{Discussion}

\section{Key Findings}

We have studied the clinical impact of VAC and IVAC in the VAE criteria and VAP in the CDC's 2008 definition in 404 subjects who required mechanical ventilation for $\geq 4 \mathrm{~d}$. IVAC was independently associated with hospital mortality. Although not statistically significant, VAC also tended to show a similar association with hospital mortality. On the other hand, VAP was not associated with hospital death.

\section{Relationship to Previous Studies}

There are several previous studies on the epidemiology and clinical impact of VAE. ${ }^{10-16,19}$ The incidence of VAC and IVAC was reported to be approximately 5-10\% and $3-5 \%$, respectively, similar to our results (VAC $13.4 \%$, IVAC 5.7\%). ${ }^{10,12,13,19}$ These previous studies consistently found that the relationship among VAC, IVAC, and con- 


\section{VAEs in CRitically Ill SubJects With PMV}

Table 2. Clinical Course and Outcomes of VAEs and VAP Subjects

\begin{tabular}{|c|c|c|c|c|c|}
\hline & All Subjects & VAC & IVAC & VAP & Without VAEs and VAP \\
\hline Subjects, $n(\%)$ & $404(100)$ & $54(13.4)$ & $23(5.7)$ & $20(5.0)$ & $338(83.7)$ \\
\hline Hosp-ICU, d (IQR) & $5(0-16)$ & $5.5(2-15) \dagger$ & $4(2-18) \dagger$ & $6.5(1.3-7.8) \dagger$ & $5(0-18)$ \\
\hline ICU readmission, $n(\%)$ & $77(19.1)$ & $8(14.8)$ & $4(17.4)$ & $3(15.0)$ & $67(19.8)$ \\
\hline Tracheostomy, $n(\%)$ & $132(32.7)$ & $18(33.3)$ & $7(30.4)$ & $7(35.0)$ & $109(32.2)$ \\
\hline Renal replacement therapy, $n(\%)$ & $113(28.0)$ & $25(46.3)^{*}$ & $14(60.9)^{*}$ & $5(25.0)$ & $88(26.0)$ \\
\hline Duration of mechanical ventilation, $\mathrm{d}$ (IQR) & $7(5-12)$ & $15(7-23) \dagger$ & $13(9-21) \dagger$ & $11(8-17) \dagger$ & $6(4-9)$ \\
\hline ICU discharge alive & $7(5-10)$ & $14(8-20)^{*}$ & $10(9-15)$ & $9(8-12)^{*}$ & $5(4-8)$ \\
\hline ICU discharge dead & $11(6-21)$ & $15(7-24)$ & $13(8-23)$ & $27(23-35)$ & $8(5-20)$ \\
\hline ICU LOS, d (IQR) & $11(7-17)$ & $17(11-23) \dagger$ & $15(12-22) \dagger$ & $14(13-22) \dagger$ & $10(7-15)$ \\
\hline ICU discharge alive & $11(7-15)$ & $17(12-24)^{*}$ & $17(13-20)^{*}$ & $13(11-16)^{*}$ & $10(7-15)$ \\
\hline ICU discharge dead & $12(6-23)$ & $15(10-23)$ & $14(11-21)$ & $26(23-34)$ & $10(5-21)$ \\
\hline Hospital LOS, d (IQR) & $63(33-119)$ & $47(31-122) \dagger$ & $47(16-88) \dagger$ & $74(41-123) \dagger$ & $63(33-120)$ \\
\hline Hospital discharge alive & $72(42-126)$ & $95(59-224) *$ & $102(63-219)$ & $82(62-129)$ & $68(41-121)$ \\
\hline Hospital discharge dead & $43(17-98)$ & $38(16-65)$ & $38(14-65)$ & $36(30-39)$ & $53(20-103)$ \\
\hline ICU mortality, $n(\%)$ & $74(18.3)$ & $26(48.1)^{*}$ & $14(60.9)^{*}$ & $5(25.0)$ & 47 (13.9) \\
\hline Hospital mortality, $n(\%)$ & $150(37.1)$ & $31(57.4)^{*}$ & $15(65.2)^{*}$ & $5(25.0)$ & $118(34.9)$ \\
\hline $\begin{array}{l}\text { * } P<.05 \text { in the comparison to "Without VAE and VAP" } \\
\dagger \text { The comparison between the Without-VAE and VAP gro } \\
\text { Fisher exact test and } t \text { test were performed in the comparis } \\
\text { VAC = ventilator-associated condition, including IVAC } \\
\text { IVAC = infection-related ventilator-associated complicatio } \\
\text { VAP = ventilator-associated pneumonia in Centers for Dis } \\
\text { VAE = ventilator-associated event } \\
\text { Hosp-ICU: duration from hospital admission to ICU admis } \\
\text { IQR = interquartile range (25th to 75th percentiles) } \\
\text { ICU readmission: ICU readmission within consecutive hos } \\
\text { LOS: length of stay }\end{array}$ & $\begin{array}{l}\text { Control and Preventi } \\
\text { categorical data and }\end{array}$ & $\begin{array}{l}\text { the interpretation d } \\
\text { tinuous data, respect } \\
008 \text { criteria }\end{array}$ & ds on the status of di & rge (alive or dead). & \\
\hline
\end{tabular}

Table 3. Association Between ICU Events and VAEs and VAP

\begin{tabular}{lrrr}
\hline \hline \multirow{2}{*}{ ICU Event } & \multicolumn{3}{c}{ Number of Events (\%), Odds Ratio (95\% CI) } \\
\cline { 2 - 4 } & \multicolumn{1}{c}{ VAC $n=54$} & IVAC $n=23$ & VAP $n=20$ \\
\hline ICU readmission, $n=77$ & $8(15 \%), 0.71(0.32-1.57)$ & $4(17 \%), 0.89(0.29-2.69)$ & $3(15 \%), 0.74(0.21-2.59)$ \\
Tracheostomy, $n=132$ & $18(33 \%), 1.04(0.56-1.90)$ & $7(30 \%), 0.90(0.36-2.23)$ & $7(35 \%), 1.12(0.43-2.87)$ \\
Renal replacement therapy, $n=113$ & $25(46 \%), 2.57(1.43-4.62)$ & $14(61 \%), 4.43(1.86-10.56)$ & $5(25 \%), 0.85(0.30-3.13)$ \\
& & & \\
$N=404$ & & & \\
VAE $=$ ventilator-associated event & & \\
VAP $=$ ventilator-associated pneumonia in Centers for Disease Control and Prevention 2008 criteria & & \\
VAC $=$ ventilator-associated condition, including IVAC & & \\
IVAC $=$ infection-related ventilator-associated complication \\
ICU readmission: ICU readmission within consecutive hospitalization
\end{tabular}

ventional VAP was poor, and that VAE was associated with adverse outcomes. However, the duration of mechanical ventilation in these studies was shorter than the minimal requirement of $4 \mathrm{~d}$ in the VAE definition. The shorter duration of mechanical ventilation in those studies might have affected the assessment of clinical outcomes of VAEs.

To our knowledge, there are only a few studies in which study cohorts met the minimal requirement of the duration of mechanical ventilation to diagnose VAE. Lilly et al ${ }^{20}$ studied the prevalence and characteristics of VAEs in 8,408 adult subjects who required mechanical ventilation for at least 10 min in 7 ICUs. They included 2,857 subjects who required mechanical ventilation for $\geq 4 \mathrm{~d}$ to identify $\mathrm{VAC}$ and IVAC, and 3,313 subjects who required mechanical ventilation for $\geq 3 \mathrm{~d}$ to identify VAP. They demonstrated that the odds ratios for in-hospital mortality for VAC, IVAC, and VAP after adjustment for disease severity and type of ICU were not statistically significant (odds ratios: VAC 1.84, IVAC 1.32, VAP 1.03). However, in the analysis for in-hospital mortality, all mechanically ventilated subjects who required mechanical ventilation for at least $10 \mathrm{~min}$ were used as the reference. Including mechanical 


\section{VAEs in CRitically Ill SubJects With PMV}

Table 4. Multivariable Hazards Model for Hospital Mortality

\begin{tabular}{|c|c|c|c|c|c|c|}
\hline & $\mathrm{VAC}(n=54)$ & $P$ & $\operatorname{IVAC}(n=23)$ & $P$ & $\operatorname{VAP}(n=20)$ & $P$ \\
\hline Crude mortality, $n(\%)$ & $31(57.4)$ & & $15(65.2)$ & & $5(25.0)$ & \\
\hline Hazard ratio $(95 \% \mathrm{CI})$ & $1.61(1.08-2.40)$ & .02 & $2.27(1.33-3.88)$ & .003 & $0.70(0.29-1.71)$ & .43 \\
\hline Adjusted hazard ratio by confounders $(95 \% \mathrm{CI})$ & $1.45(0.97-2.18)$ & .07 & $2.42(1.39-4.20)$ & .002 & $1.08(0.44-2.66)$ & .87 \\
\hline \multicolumn{7}{|l|}{ Confounding variables, hazard ratio $(95 \% \mathrm{CI})$} \\
\hline Weight, kg & $0.99(0.98-1.00)$ & .02 & $0.98(0.97-1.00)$ & .01 & $0.99(0.98-1.00)$ & .030 \\
\hline Male (vs female) & $1.55(1.05-2.29)$ & .030 & $1.52(1.03-2.25)$ & .036 & $1.54(1.04-2.28)$ & .030 \\
\hline APACHE II score, point & $1.08(1.06-1.10)$ & $<.001$ & $1.09(1.06-1.11)$ & $<.001$ & $1.09(1.06-1.11)$ & $<.001$ \\
\hline Liver failure & $3.91(1.80-8.52)$ & $<.001$ & $3.66(1.68-8.00)$ & .001 & $3.49(1.52-8.04)$ & $<.001$ \\
\hline Metastatic cancer & $3.64(1.58-8.38)$ & .002 & $3.72(1.62-8.58)$ & .002 & $3.70(1.60-8.53)$ & .003 \\
\hline \multicolumn{7}{|c|}{$\begin{array}{l}\text { VAC }=\text { ventilator-associated condition, including IVAC } \\
\text { IVAC }=\text { infection-related ventilator-associated complication } \\
\text { VAP }=\text { ventilator-associated pneumonia in Centers for Disease Control and Prevention } 2008 \text { criteria } \\
\text { APACHE }=\text { acute physiology and chronic health evaluation }\end{array}$} \\
\hline
\end{tabular}

Table 5. Association Between Hospital Mortality and Characteristics of VAE and VAP Subjects

\begin{tabular}{|c|c|c|c|}
\hline Characteristics, Hospital Mortality, $n / N(\%)$ & & $\begin{array}{c}\text { Hospital Mortality } \\
n / N(\%), \text { Odds Ratio }(95 \% \mathrm{CI})\end{array}$ & \\
\hline All subjects, 150/404 (37.1) & VAC, $31 / 54$ (57.4) & IVAC, $15 / 23(65.2)$ & VAP, $5 / 20(25.0)$ \\
\hline \multicolumn{4}{|l|}{ Admission type } \\
\hline Emergency surgery, 30/91 (33.0) & $2 / 8(25.0), 0.66(0.12-3.46)$ & $1 / 4(25), 0.67(0.07-6.70)$ & $0 / 3(0), 0.27(0.014-5.48)^{*}$ \\
\hline Elective surgery, 26/120 (21.7) & $8 / 23(34.8), 2.34(0.86-6.36)$ & $4 / 9(44.4), 3.24(0.80-13.1)$ & $3 / 13(23.1), 1.10(0.28-4.31)$ \\
\hline Non-operative, 94/193 (48.7) & $21 / 23(91.3), 14.0(3.17-61.4)$ & $10 / 10(100), 24.7(1.43-428)^{*}$ & $2 / 4(50.0), 1.05(0.15-7.64)$ \\
\hline \multicolumn{4}{|l|}{ Comorbidities } \\
\hline Immunocompromised, 29/46 (63.0) & 7/9 (77.8), $2.39(0.43-13.1)$ & $4 / 4(100), 6.18(0.31-41.3)^{*}$ & $0 / 1(0), 0.19(0.007-4.84)^{*}$ \\
\hline Metastatic cancer, 6/11 (54.5) & $1 / 1(100), 3.00(0.10-91.0)^{*}$ & $\mathrm{NA} \dagger, 0.85(0.01-50.1)^{*}$ & $\mathrm{NA} \dagger, 0.85(0.01-50.1)^{*}$ \\
\hline Hematologic malignancy, 19/22 (86.4) & $4 / 4(100), 2.03(0.09-47.1)^{*}$ & $2 / 2(100), 1.00(0.04-25.7)^{*}$ & $\mathrm{NA} \dagger, 0.18(0.003-10.6)^{*}$ \\
\hline End-stage kidney disease, 20/44 (45.5) & $4 / 7(57.1), 1.75(0.34-8.95)$ & $2 / 4(50.0), 1.22(0.16-9.56)$ & $1 / 3(33.3), 0.58(0.05-6.90)$ \\
\hline Liver failure, $7 / 9(77.8)$ & $2 / 2(100), 2.27(0.08-67.1)^{*}$ & $2 / 2(100), 2.27(0.08-67.1)^{*}$ & $0(0), 0.33(0.005-21.6)^{*}$ \\
\hline \multicolumn{4}{|c|}{$\begin{array}{l}\text { * Modified odds ratio is presented because of zero-cell counts in two-by-two contingency table. } \\
\dagger \text { No subjects were identified IVAC or VAP. } \\
\text { VAE }=\text { ventilator-associated event } \\
\text { VAP }=\text { ventilator-associated pneumonia in Centers for Disease Control and Prevention } 2008 \text { criteria } \\
\text { VAC }=\text { ventilator-associated condition, including IVAC } \\
\text { IVAC }=\text { infection-related ventilator-associated complication }\end{array}$} \\
\hline
\end{tabular}

ventilation duration $<4 \mathrm{~d}$ in their analysis may have affected their results. The OUTCOMEREA Study Group ${ }^{21}$ studied VAE epidemiology and clinical outcomes in 3,028 critically ill adult subjects on mechanical ventilation for at least 5 consecutive days. They found that VAC and IVAC were associated with longer ventilation days, prolonged ICU and hospital stay, and an increase in the total antimicrobial consumption. The crude rates of hospital mortality for VAC, IVAC, and non-VAC were similar among the 3 groups (VAC 36.7\%, IVAC 44.4\%, non-VAC 39.9\%). However, they modified the VAE definition presented by the CDC for the deterioration of oxygenation $\left(\mathrm{P}_{\mathrm{aO}} / \mathrm{F}_{\mathrm{IO}_{2}}\right.$ ratio and PEEP level instead of increase in daily minimum $\mathrm{F}_{\mathrm{IO}_{2}}$ and PEEP values). ${ }^{9}$ This modification makes the comparison of their results with other studies, including ours, difficult. Furthermore, several studies decreased the time-related selection bias by their statistical methods. Klompas et al ${ }^{5,6,22}$ matched the duration of mechanical ventilation in ventilated control subjects for as long as the time to VAE onset to reduce the impact of the different duration of mechanical ventilation on the clinical outcomes. Other studies used time-varying statistical methods to account for time to onset of VAE. ${ }^{11,13}$ In our study, we not only limited study subjects to those who met the minimal requirement of mechanical ventilation duration for VAE diagnosis, but we also used the time-varying statistical method to account for time to onset of VAE/VAP for the impact on hospital mortality.

\section{Significance and Implications}

In subjects with mechanical ventilation for $\geq 4 \mathrm{~d}$, IVAC was associated with hospital mortality, whereas VAP was 


\section{VAEs in CRitically Ill SubJects With PMV}

not (Table 4). The more critically ill subjects might be picked up by VAE surveillance rather than by that of VAP (Table 1, 2, 5). Furthermore, the VAE definition can facilitate automated surveillance because of the requirement for objective data. ${ }^{8} 9$ We believe that VAE is more appropriate for use as a surveillance tool than previous 2008 VAP in critically ill patients who require prolonged mechanical ventilation.

However, it is uncertain whether VAE is a remarkable quality indicator or merely a marker of disease severity in ventilated patients. In general, a quality indicator is necessary to evaluate preventability of a certain intervention. The preventability of VAE has been investigated in recent studies, and early liberation from mechanical ventilation has been suggested for preventing VAE. ${ }^{23-25}$ Further studies for the preventability of VAE are needed to develop new bundles of care for ventilated patients.

\section{Strengths and Limitations}

Different from many previous studies, ${ }^{10-16}$ all subjects in our study met the minimal requirement of $\geq 4 \mathrm{~d}$ on mechanical ventilation to diagnose VAE. We also used the time-varying statistical method to reduce the major confounding factor of prolonged mechanical ventilation and greater risk of poor outcomes. Furthermore, in our study, there was no censoring, and all subjects were followed up until hospital discharge. To our knowledge, the finding that a renal replacement therapy requirement was strongly associated with VAC and IVAC (Table 3) has not been examined in previous studies. Further prospective studies are needed to evaluate a causal relationship between VAE and a renal replacement therapy requirement.

Our study also has several limitations. First, the generalizability of our findings could be limited because our work was retrospective research conducted in a single center in Japan. However, all subjects in our study met the minimal requirement of the duration of mechanical ventilation to diagnose VAE, and we used the time-varying statistical method for the impact of VAE/VAP on mortality. Although this is a small, single-center study, this work also provides useful information for epidemiology and outcomes of VAE. Second, possible VAP in the VAE criteria was not investigated due to semiquantitative microbiological data without a count of neutrophils and squamous epithelial cells for sputum culture in our laboratory. Furthermore, not all VAE subjects were screened for microbiological cultures. These limitations made it difficult to diagnose possible VAP and compare with VAP using the CDC's 2008 criteria. Finally, we did not investigate the detailed causes of VAE. The various causes of deterioration of oxygenation in subjects with VAE have been reported in previous studies. ${ }^{12,13,20,21}$ Although it is important to detect causes of respiratory deterioration to treat patients in the clinical setting, it is not known what interventions can lead to VAE prevention. Further studies are necessary to identify the causes of VAE.

\section{Conclusions}

We have found that VAE is related to hospital mortality in critically ill subjects on prolonged mechanical ventilation and that VAP is not. AVAE, especially an IVAC, is a reasonable marker for surveillance in mechanically ventilated patients.

\section{ACKNOWLEDGMENTS}

We thank the Infection Control Team of Jikei University Hospital for providing data for ventilator-associated pneumonia surveillance during the study period. We thank Dr M. Nishikawa, from the Clinical Research Support Center of Jikei University, for statistical support.

\section{REFERENCES}

1. Horan TC, Andrus M, Dudeck MA. CDC/NHSN surveillance definition of health care-associated infection and criteria for specific types of infections in the acute care setting. Am J Infect Control 2008;36(5):309-332. Erratum in: Am J Infect Control 2008;36(9): 655.

2. Fàbregas N, Ewig S, Torres A, El-Ebiary M, Ramirez J, de La Bellacasa JP, et al. Clinical diagnosis of ventilator associated pneumonia revisited: comparative validation using immediate post-mortem lung biopsies. Thorax 1999;54(10):867-873.

3. Klompas M. Dose this patient have ventilator-associated pneumonia? JAMA 2007;297(14):1583-1593.

4. Klompas M, Platt R. Ventilator-associated pneumonia: the wrong quality measure for benchmarking. Ann Intern Med 2007;147(11): 803-805.

5. Klompas M, Khan Y, Kleinman K, Evans RS, Lloyd JF, Stevenson $\mathrm{K}$, et al; on behalf of the CDC Prevention Epicenters Program. Multicenter evaluation of a novel surveillance paradigm for complications of mechanical ventilation. PLoS ONE 2011;6(3):e18062.

6. Klompas M, Magill S, Robicsek A, Strymish JM, Kleinman K, Evans RS, et al; on behalf of the CDC Prevention Epicenters Program. Objective surveillance definitions for ventilator-associated pneumonia. Crit Care Med 2012;40(12):3154-3161.

7. Grgurich PE, Hudcova J, Lei Y, Sarwar A, Craven DE. Diagnosis of ventilator-associated pneumonia: controversies and working toward a gold standard. Curr Opin Infect Dis 2013;26(2):140-150.

8. Klompas M. Complications of mechanical ventilation: the CDC's new surveillance paradigm. N Engl J Med 2013;368(16):1472-1475.

9. Magill SS, Klompas M, Balk R, Burns SM, Deutschman CS, Diekema $\mathrm{D}$, et al. Developing a new, national approach to surveillance for ventilator-associated events. Crit Care Med 2013;41(11):2467-2475.

10. Muscedere J, Sinuff T, Heyland DK, Dodek PM, Keenan SP, Wood G, et al; on behalf of the Canadian Critical Care Trials Group. The clinical impact and preventability of ventilator-associated conditions in critically ill patients who are mechanically ventilated. Chest 2013; 144(5):1453-1460.

11. Hayashi Y, Morisawa K, Klompas M, Jones M, Bandeshe H, Boots $\mathrm{R}$, et al. Toward improved surveillance: the impact of ventilatorassociated complications on length of stay and antibiotic use in patients in intensive care units. Clin Infect Dis 2013;56(4):471-477.

12. Boyer AF, Schoenberg N, Babcock H, McMullen KM, Micek ST, Kollef MH. A prospective evaluation of ventilator-associated con- 


\section{VAEs in CRitically Ill SubJects With PMV}

ditions and infection-related ventilator-associated conditions. Chest 2015;147(1):68-81.

13. Klouwenberg PMCK, van Mourik MSM, Ong DSY, Horn J, Schultz MJ, Cremer OL, et al; on behalf of the MARS Consortium. Electronic implementation of a novel surveillance paradigm for ventilator-associated events: feasibility and validation. Am J Respir Crit Care Med 2014;189(8):947-955.

14. Prospero E, Illuminanti D, Marigliano A, Pelaia P, Munch C, Barbadoro P, D'Errico MM. Learning from Galileo: ventilator-associated pneumonia surveillance (letter). Am J Respir Crit Care Med 2012;186(12):1308-1309.

15. Piriyapatsom A, Lin H, Pirrone M, De Pascale G, Corona De Lapuerta J, Bittner EA, et al. Evaluation of the infection-related ventilatorassociated events algorithm for ventilator-associated pneumonia surveillance in a trauma population. Respir Care 2016;61(3):269-276.

16. McMullen KM, Boyer AF, Schoenberg N, Babcock HM, Micek ST, Kollef MH. Surveillance versus clinical adjunction: differences persist with new ventilator-associated event definition. Am J Infect Control 2015;43(6):589-591.

17. Knaus WA, Draper EA, Wagner DP, Zimmerman JE. APACHE II: a severity of disease classification system. Crit Care Med 1985; 13(10):818-829.

18. Haldane JB. The estimation of significance of the logarithm of a ratio of frequencies. Ann Hum Genet 1956;20(4):309-311.

19. Stevens JP, Silva G, Gillis J, Novack V, Talmor D, Klompas M, Howell MD. Automated surveillance for ventilator-associated events. Chest 2014;146(6):1612-1618.
20. Lilly CM, Landry KE, Sood RN, Dunnington CH, Ellison RT 3rd, Bagley PH, et al; on behalf of the UMass Memorial Critical Care Operations Group. Prevalence and test characteristics of national health safety network ventilator-associated events. Crit Care Med 2014;42(9):2019-2028.

21. Bouadma L, Sonneville R, Garrouste-Orgeas M, Darmon M, Souweine B, Voiriot G, et al; on behalf of the OUTCOMEREA Study Group. Ventilator-associated events: prevalence, outcome, and relationship with ventilator-associated pneumonia. Crit Care Med 2015; 43(9):1798-1806.

22. Klompas M, Kleinman K, Murphy MV. Descriptive epidemiology and attributable morbidity of ventilator-associated events. Infect Control Hosp Epidemiol 2014;35(5):502-510.

23. Klompas M, Anderson D, Trick W, Babcock H, Kerlin MP, Li L, et al; on behalf of the CDC Prevention Epicenters. The preventability of ventilator-associated events. The CDC Prevention Epicenters Wake Up and Breathe Collaborative. Am J Respir Crit Care Med 2015; 191(3):292-301.

24. Damas P, Frippiat F, Ancion A, Canivet JL, Lambermont B, Layios $\mathrm{N}$, et al. Prevention of ventilator-associated pneumonia and ventilator-associated conditions: a randomized controlled trial with subglottic secretion suctioning. Crit Care Med 2015;43(1):22-30.

25. Klompas M, Li L, Szumita P, Kleinman K, Murphy MV; on behalf of the CDC Prevention Epicenters Program. Associations between different sedatives and ventilator-associated events, length-of-stay, and mortality in mechanically ventilated patients. Chest 2016;149(6):1373-1379.

This article is approved for Continuing Respiratory Care Education credit. For information and to obtain your CRCE

(free to AARC members) visit www.rcjournal.com 